\title{
Erratum zu: Arbeitsraum Natur
}

\section{Erratum zu: C. Gans et al., Arbeitsraum Natur, Handbuch für Coaches, Therapeuten, Trainer und Organisationen $~-~ h t t p s: / /$ doi.org/10.1007/978-3-658-29939-2}

Definition von Begrifflichkeiten und Konzepten zur Arbeit in und mit der Natur, - https://doi.org/10.1007/978-3-658-29939-2_1

Auf S. 17 wurde ,Senkung der Anzahl und Aktivität der natürlichen Killerzellen“ korrigiert zu ,Steigerung der Anzahl und Aktivität der natürlichen Killerzellen".

Natur-Mentaltraining in der Praxis, https://doi.org/10.1007/978-3-65829939-2_6

Das mit • Abb 6.6. verknüpfte Video wurde aktualisiert.

Die aktualisierten Versionen der Kapitel können hier abgerufen werden:

- https://doi.org/10.1007/978-3-658-29939-2_1

- https://doi.org/10.1007/978-3-658-29939-2_6 